\title{
FIB/SEM Imaging of Microbial Induced Calcite Precipitation in Sandy Soil
}

\author{
Lin $\mathrm{Li}^{1}$, Kejun Wen ${ }^{1}$, Chi $\mathrm{Li}^{2}$, and Farshad Amini ${ }^{1}$ \\ ${ }^{1 .}$ Department of Civil and Environmental Engineering, Jackson State University, Jackson, MS, USA. \\ 2. Inner Mongolia University of Technology, College of Civil Engineering, Huhhot, China
}

As one of the emerging soil improvement techniques, microbial induced calcite precipitation (MICP) can bond soil grains together and improve the engineering properties of soil [1]. bacteria produces urease enzyme can catalyze urea to carbonate and result in calcite precipitation in elevated $\mathrm{pH}$ environment. The forms of calcite precipitation around the bacteria limit the availability of oxygen and nutrient to the bacteria and reduce the efficiency of bacteria in producing urease enzyme. The MICP faces challenge of non-uniformity of calcite precipitation and very limited penetration depth in the treated soil that may limit the application of this innovative soil binding technology [2-3].

The MICP process relies on molecular-level chemical and biological processes that must be better understood for large-scale implementation. Microscopy has proven to be one of the most useful analytical tools in the study, providing the ability to non-invasively visualize, differentiate, and quantify the various components. SEM has been used to examine the formation of MICP and biofilms on the surface of the soil matrix [4-5]. The objective of this study is to investigate the mineral formation in the interior of MICP-treated sandy soil with scanning electron microscopy (SEM).

Uniform, clean, Ottawa silica sand was used in the experiments. The average particle diameter of the sand $\left(\mathrm{D}_{50}\right)$ is $0.54 \mathrm{~mm}$ and no fines were included. Bacteria Sporosarcina Pasteurii was used due to its highly active urease enzyme. The cementation medium included urea, $\mathrm{CaCl}_{2} \cdot \mathrm{H}_{2} \mathrm{O}, \mathrm{NH}_{4} \mathrm{Cl}, \mathrm{NaHCO}_{3}$, and nutrient broth. The urea-Ca ${ }^{2+}$ molar ratio was fixed at 1:1. The specimens were prepared in full contact flexible molds as described in Zhao et al. (2014), which were made of geotextile. The fibrous structure of this geotextile mold can effectively increase the penetration of chemicals into sand pores and maintain a suitable precipitation that makes the MICP-treated soil samples more homogeneous. All samples were prepared in continually stirred tank reactor, as shown in Figure 1a. With the bacteria concentration $\left(\mathrm{OD}_{600}\right)$ of 0.6 and cementation concentration of $0.5 \mathrm{M}$, the samples were prepared in the reactor for 7 days. Subsequently, these samples were sputter-coated for SEM analysis and Focus ion beam FIB/SEM analysis.

Figure $1 \mathrm{~b}$ shows an example of MICP-treated soil specimens after 7 days of reaction. The SEM image of surface soil in Figure 1c shows that the $\mathrm{CaCO}_{3}$ crystals were mainly irregular bulk. Most of crystal particles were dispersed and uniformly distributed in the gap between sand particles, and sometimes there was overlapping structure on the crystal surface [4]. The FIB/SEM image (Figure 1d) was shown for the inner core of soil specimen. After FIB milling of $30 \mu \mathrm{m}$, the SEM image provides much clear and sharp image of inactive bacteria and mineral formation.

The conventional SEM only analyzes the surface of sample. After removing the first layer of specimen, the SEM image can be collected for the deeper layer. Repeating this procedure can produce the internal structure. However, during this manual trimming process, it will damage the interfacial bonding between cells and mineral. Automated trimming process along with the SEM observation is useful to study the interior structure of MICP treated soil specimen. With the milling function of FIB, the focused ion beam 
made cross section inside the MICP sample layer by layer that can be observed with SEM. The image and the determination of 3D micro- and nano-scale structure of the bio-mediated soil materials are essential for the study of bio-geo material and its applications in large-scale engineering application, as shown in Figure 1e. The destructive milling processing of FIB does not impact on the bacteria performance, because the bacteria are inactive after 7 days of reaction without adding nutrient broth and oxygen in the batch reactor.

Conventional SEM and FIB/SEM have been used in this study to investigate the mineral formation in the MICP-treated sandy soil. Both SEM images can illustrate the mineral formation in the surface of sample. With the milling function, the FIB can develop the interior structure image with the SEM for the MICP. The 3D micro- and nano-scale structures of the bio-mediated soil materials are essential for the study of bio-geo material and its applications in large-scale engineering application.

\section{References:}

[1] DeJong, J. T., Soga, K., Banwart, S. A., etc., Journal of Geotechnical and Geoenvironmental Engineering, 8(2011): p. 1.

[2] Martinez, B. C., DeJong, J. T., Ginn, T. R., etc., Journal of Geotechnical and Geoenvironmental Engineering, 139(2013), p. 587.

[3] Burbank, M., Weaver, T., Lewis, R., etc., Journal of Geotechnical and Geoenvironmental Engineering, 139(2013), p. 928.

[4] Zhao, Q., Li, L., Li, C., etc. Journal of Materials in Civil Engineering, ASCE, 26(2014), 04014094.

[5] Chou, C., Seagren E. A., Aydilek, A. H., etc. Journal of Geotechnical and Geoenvironmental Engineering, 137(2011), p. 1179.

(a)

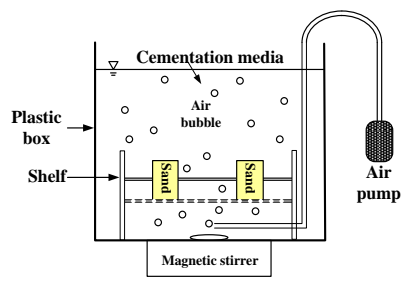

(b)

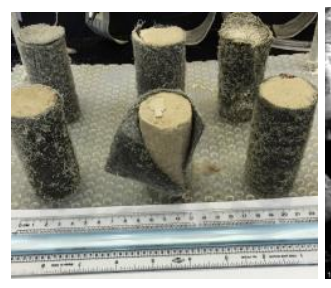

(c)

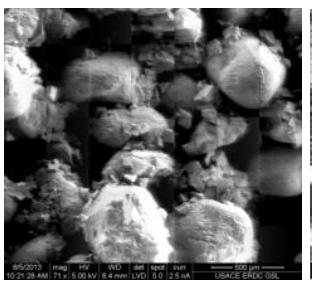

(d)

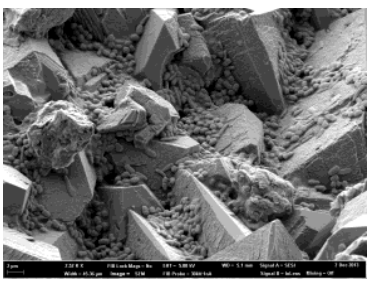

(e)

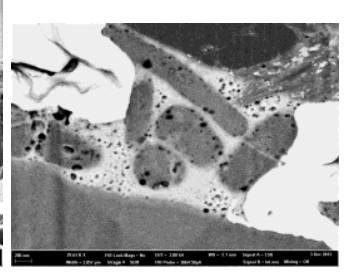

Figure 1. (a) Schematic drawing of the batch reactor, (b) Image of specimens after the reactions, (c) SEM image of the MICP-treated soil specimens, (d) FIB/SEM image of the specimen at $2000 \mathrm{~nm}$ resolution, and (e) FIB/SEM image of the specimen at $200 \mathrm{~nm}$ resolution. The full contact flexible mold outside the specimens was fabricated by geotextile. 